\title{
A techno-economical view on energy losses at hydropower dams (case study of Karun III Dam and Hydropower Plant)
}

\author{
M. Jorabloo ${ }^{1}$, M. Abdolahpour ${ }^{2}$, R. Roshan ${ }^{2} \&$ H. Sarkardeh ${ }^{2}$ \\ ${ }^{1}$ Department of Engineering, Water Engineering Group, \\ Islamic Azad University, Iran \\ ${ }^{2}$ Hydraulic Structures Division, Water Research Institute, Iran
}

\begin{abstract}
In order to support the future economic developments in the world, one of the most important objectives is the reduction of energy losses. Apart from this objective, hydropower dams which are considered a renewable energy source encounter this problem. Karun III Dam and Hydropower Plant is constructed on the Karun River in the province of Khuzestan, Iran, with a capacity of 2000 MW. The Dam is a double arch concrete type, $205 \mathrm{~m}$ high from the foundation and $185 \mathrm{~m}$ high from the river bed. In the present work by using the physical model of Karun III Dam and measuring pressures in all parts of conveyance members, energy losses for each part were calculated separately. Experiments were conducted in three different elevations and with maximum design discharge. By calculating the cavitation index along the related hydraulic structures, probability of cavitation was studied. Discharge coefficient was also estimated in the operation conditions. Experiments showed that when the reservoir elevation was increased in constant discharge; the discharge coefficient was increased respectively. Also it was observed that increasing the reservoir elevation causes head losses to increase in different parts of conveyance members except the antivortex structure which was installed at the top of the intake. Moreover, energy losses at the Y-Branch member were observed more than other parts.
\end{abstract}

Keywords: Karun III Dam and Hydropower Plant, energy losses, physical model, cavitation. 


\section{Introduction}

Dams are constructed for different purposes. The most important targets could be the supply of drinking water, industrial, irrigation, power generation, prevention of floods, providing hydraulic head and also recreation purposes. Meanwhile, use of dams is a safe and green way for power generation [1]. It is clear that the occurrence of energy losses in hydraulic structures is inevitable. Minimizing the losses can lead to an increase of energy generation in hydropower plants. Some of the important structures in view of energy losses are intakes, tunnels, transitions and Y-branches. In the flow path two types of losses are expected: friction losses and local losses. Friction losses or longitudinal losses caused by passing the flow over the surface roughness. Darcy-Weisbach presented the following equation to calculate the head losses along the pressure conduits [2]:

$$
\mathrm{h}_{\mathrm{f}}=\mathrm{f} \frac{\mathrm{L}}{\mathrm{D}} \frac{\mathrm{V}^{2}}{2 \mathrm{~g}}
$$

where $h_{f}$ is longitudinal head losses, $f$ is Darcy-Weisbach Coefficient, $D$ is the diameter, $L$ is the length and $V$ is flow velocity in the tunnel.

Since, the head losses due to suddenly changes occur in the flow pass, the following equation calculates the head of energy losses [2]:

$$
\mathrm{h}_{\mathrm{f}}=\mathrm{k} \frac{\mathrm{V}^{2}}{2 \mathrm{~g}}
$$

where $K$ is local head loss coefficient.

To calculate power generation in a hydropower plant the following equation can be used:

$$
\mathrm{P}=\gamma \mathrm{QH}
$$

where $P$ is the generated power, $\gamma$ is the specific gravity of the water, $Q$ is flow rate and $H$ is water head.

According to the Bernoulli Equation, the discharge coefficient can be calculated. By summarizing related equations, discharge coefficient is as follows:

$$
\begin{gathered}
\mathrm{C}_{\mathrm{d}}=\frac{\mathrm{V}}{2 \mathrm{~g}\left(\mathrm{~h}+\mathrm{h}_{\mathrm{f}}-\frac{\mathrm{P}}{\gamma}\right)} \\
\mathrm{K}=\frac{1}{\mathrm{C}_{\mathrm{d}}^{2}}-1
\end{gathered}
$$

where $C_{d}$ is discharge coefficient, $h$ is the water depth over the intake (the distance between the centerline of the intake and water surface).

Cavitation is a phenomenon which may cause damage and cavity in hydraulic structures at high velocities. Sometimes in a hydraulic system, because of increasing velocity and existing small roughness at flow walls, pressure 
decreases. Decreasing local pressure may cause vapor pressure and creation of bubbles. Produced bubbles, distribute in the flow and transport farther, a place with high pressure. In this time, they will explode and produce noise and huge impact stresses into the walls. Due to the impact of exploded bubbles, walls may face serious damage that is known as "Cavitation phenomenon". In some cases the bubbles explode at the site of creation because of unstable flow regimes and leads to destruction just in place.

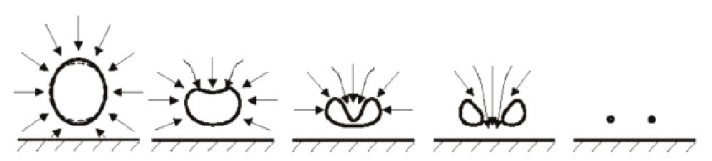

Figure 1: Schematic view of cavitation process.

Existence of swirling flows can lead to a decrease in the turbine efficiency, introducing vibration in the system, increasing hydraulic losses at the entrance of power intakes, blocking the trashrack and tunnels because of air suction and floating materials from the reservoir, and finally reduction of turbine life [3]. In this regard, using the anti-vortex structures in dams is recommended. Based on Sarkardeh et al. [4], vortices are divided into three classes. Vortices Class C are observed as a weak rotation of flow at water surface and in addition to water surface rotation a drop may also be observed in water surface. In vortices Class $\mathrm{B}$ the rotation of flow is extended down to the intake itself and in stronger position, dragging debris and trash into the intake is expected. In Class A vortices, some air bubbles are entrained from water surface and are transported down to the intake and in the strongest vortices, a stable air core is formed in the center of the vortex and air is entrained into the tunnel steadily.

Investigation on hydropower energy losses in the various structures has been considered by some researchers. In the present work by using the physical model of Karun III Dam, head losses at all parts due to power generation from reservoir to turbine, discharge coefficient in the presence of anti-vortex walls. Moreover, cavitation probability was investigated at the all parts of the conveyance structures. Experiments were conducted in three different elevations and with maximum design discharge.

\section{Experimental works}

All experiments were carried out on the physical model of the Karun III Dam and Hydropower Plant. The Dam is constructed on the Karun River in the province of Khuzistan, Iran, with the capacity of 2000 MW. The Dam is a double arch concrete type, $205 \mathrm{~m}$ high from the foundation and $185 \mathrm{~m}$ high from the river bed. The power plant consisted of 8 units, each unit supply the capacity of $250 \mathrm{MW}$. The physical model of Dam and its hydropower plant were constructed to the scale of 1:33.3. This scale was selected considering the presented criteria by Anwar et al. and Jain et al. to prevent scale effects $[5,6]$. 
Hydraulic model of Karun III Dam power intakes were included: parts of the dam reservoir, intakes, power tunnels, braches (Figures 2 and 3). The model has two power tunnels with $38 \mathrm{~cm}$ diameter (power tunnel 1) (Figure 3). Design discharge of each intake in the model was $110 \mathrm{lit} / \mathrm{s}$. Considering the design discharge, dimensions of the intakes were selected $104 \mathrm{~cm}$ height and $52 \mathrm{~cm}$ width. Maximum and minimum depth of water over the intake center line was $1.80 \mathrm{~m}$ and $0.60 \mathrm{~m}$ respectively. Experiments showed that at $0.90 \mathrm{~m}$ depth, stable vortices of Class B were formed at the intakes. Since scale effects in the physical model may reduce the type of the vortex so formation of vortex Class A is probable in the prototype.

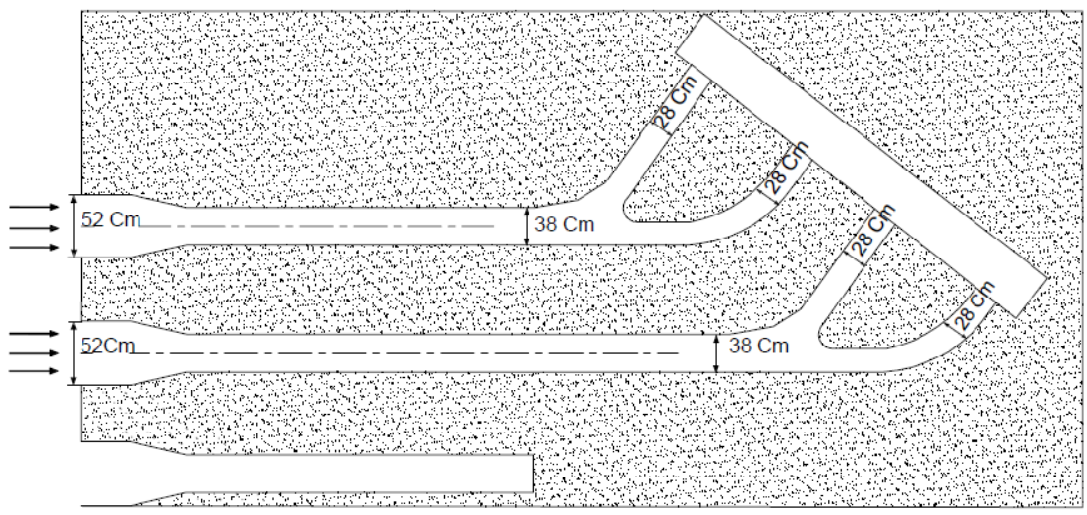

Figure 2: Plan view of convenience structures from the reservoir to the turbine of Karun III Dam.

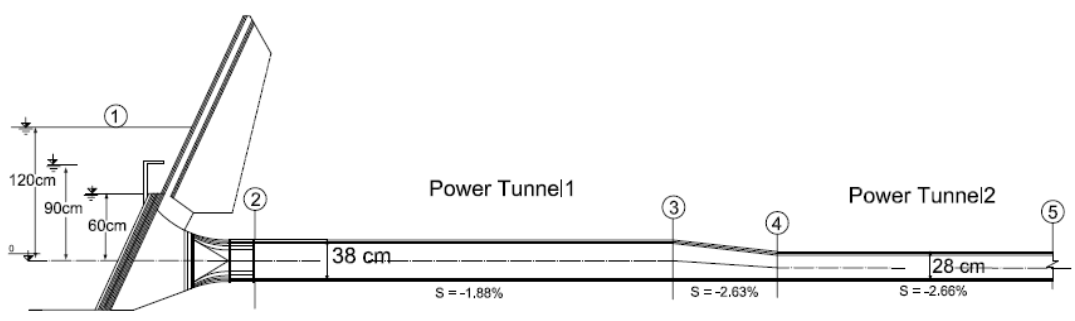

Figure 3: Side view of the convenience structures from reservoir to turbine of Karun III Dam.

To measure the flow discharge in the model, four rectangular weirs were calibrated and used for each unit. Water level of the reservoir was measured by a point gauge with accuracy of $0.1 \mathrm{~mm}$. All experiments were carried out in the three different depths of $0.60 \mathrm{~m}, 0.90 \mathrm{~m}$ and $1.20 \mathrm{~m}$ from the intake center line with a flow rate equal to $110 \mathrm{lit} / \mathrm{s}$ in the model at each intake. In order to 
investigate the real condition, all the experiments had been done in the presence of designed anti-vortex walls [7].

\section{Results and discussions}

Experiments showed that vortices were formed on the top of the intakes at a depth of $0.90 \mathrm{~m}$ above the intake center line, since strong and stable vortices were observed in the model operation at depth less than $0.90 \mathrm{~m}$ using of antivortex structure was necessary. Anti-vortex structures can be used for elimination or reduction of vortex in dams. Previous researches by Sarkardeh et al. [7] showed that groove vertical anti-vortex walls have a better performance in reducing vortex rather than continuous vertical anti-vortex walls. Therefore, groove vertical anti-vortex walls were selected as the final alternative.

\subsection{Measuring discharge coefficient}

In order to calculate discharge coefficient in power intakes of Karun III Dam with installing anti-vortex walls, pressure values were measured in a section immediately after the intake entrance (Figure 3, Section 2). In the next step, discharge coefficients were calculated by Equation (4) at different depths of $0.60 \mathrm{~m}, 0.90 \mathrm{~m}$ and $1.20 \mathrm{~m}$ above the intake center line (Figure 4).

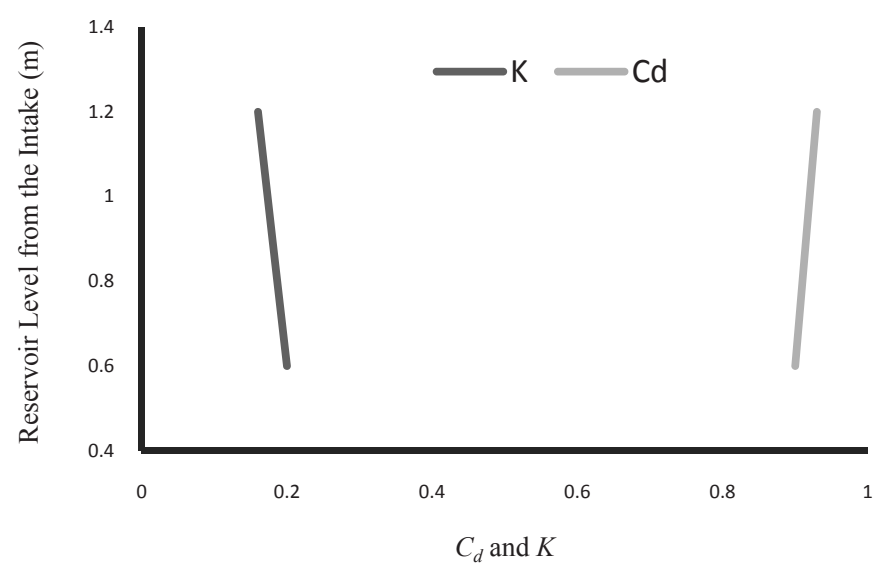

Figure 4: $\quad C_{d}$ and $K$ of the intake in presence of anti-vortex structure.

Results showed that by increasing the water level in the reservoir, discharge coefficient was increased, but this increase was not considerable. So it could be said that anti-vortex walls have no meaningful effect on the discharge coefficient in different water levels.

According to conducted experiments at three different levels of reservoir elevation $(0.60,0.90$ and $1.20 \mathrm{~m}$ ), the pressure values (by using about 400 
piezometers) showed that the probability of cavitation was not exist along the different convenience structures.

\subsection{Calculating head losses due to power generation}

One of the most important and effective parameters in hydropower dam design is the maximum use of the power of the water over the dam. So calculation of hydraulic head losses in the related structures has a great importance [8]. To calculate head losses along the structures, experiments were carried out with three different water levels, constant discharge and with presence of anti-vortex walls. Five different sections were used for measuring the pressure values (Figure 3). According to the Figure 5, it can be concluded that by increasing the water surface depth, head losses will increase respectively.

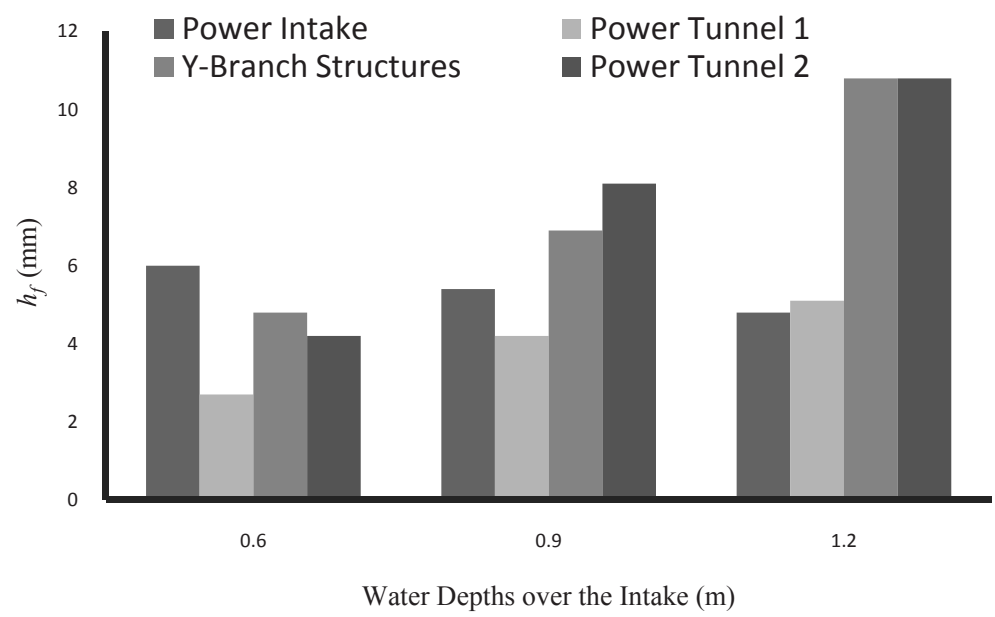

Figure 5: Head loss in different structures and reservoir levels.

This increasing trend is similar in different structures except power intake (in presence of anti-vortex device). Decreasing trend of head loss in intake inlet could be caused by the effect of anti-vortex wall in different intake levels. Maximum head loss is related to the depth of $1.20 \mathrm{~m}$ of the reservoir at the $\mathrm{Y}$ branch structure and power tunnel 2 .

Economical analysis of the project is very important in the engineering design process, especially in dam design. By using Equation 3, the amount of energy could be calculated in this project. Figure 6 shows the power loss due to power generation in the Dam.

As can be seen from Figure 6, the total head loss will increase by increasing the reservoir elevation. This figure could show to the engineers how hydraulic head losses could lead to a great amount of power lost in the hydropower plants in the prototype. 


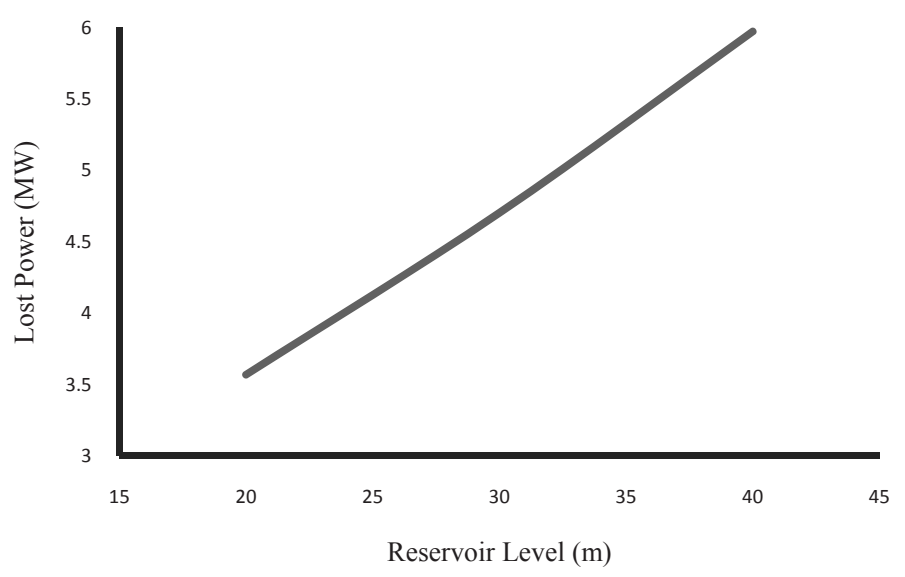

Figure 6: Total power losses in different reservoir levels of Karun III Dam.

\section{Summary and conclusion}

In the present study by using the physical model of Karun III Dam and Hydropower Plant, energy losses were calculated due to the energy generation process. The hydraulic model consisted of an anti-vortex structure, power intake, transition structure, power tunnel with $38 \mathrm{~cm}$ diameter in the model, Y-branch structure and finally power tunnel with $28 \mathrm{~cm}$ diameter in the model. Experiments were performed in three different reservoir levels and in maximum design discharge. Experiments showed that the Y-branch structure has most energy loss among the other structures. Occurrence of cavitation is a very important factor in safety of hydraulic structures. In this regard, the pressures were measured in different points of structures. The probability of cavitation was ruled out of possibility.

\section{Acknowledgement}

The authors would like to thank from the Water Research Institute (WRI) for their kind co-operation and using data.

\section{References}

[1] ASCE, Committee on Hydropower Intakes of the Energy Division, (1995), "Guidelines for Design of Intakes for Hydroelectric Plants", published by ASCE, New York.

[2] White, F.M. (1991), "Fluid Mechanics", McGraw-Hill.

[3] Knauss, J. (1987), "Swirling Flow Problems at intakes", Balkema. 
[4] Sarkardeh, H., Zarrati, A.R., Roshan, R., (2010), "Effect of intake head wall and trash rack on vortices", Journal of Hydraulic Research Vol. 48, No. 1, pp. 108-112.

[5] Anwar, H.O., Weller, J.A. and Amphlett, M.B. (1978), "Similarity of Free Vortex at Horizontal Intake", Journal of Hydraulic Research, No. 2, pp 95-105.

[6] Jain, A.K., Raju, K.G.R and Grade, R.J. (1987), "Vortex Formation at Vertical Pipe Intake", Journal of Hydraulic Engineering, Vol. 100, No. 10, pp 1427-1445.

[7] Sarkardeh, H., Safavi, K., Karaminejad, R., H.M. Azamathulla, (2009), "Prevention of Vortex Formation at Karun III Power Tunnels", 5th National Civil Engineering Conference AWAM '09), Malaysia.

[8] Sarkardeh, H. (2007), "Hydraulics of Power Tunnels and its Effect on Power Generation", M.Sc. Seminar, Amirkabir University of Technology (Tehran Polytechnic). 